\title{
Biologia reprodutiva e ecologia de Aegla leptodactyla Buckup \& Rossi (Crustacea, Anomura, Aeglidae)
}

\author{
Clarissa Köhler Noro ${ }^{2}$ \\ Ludwig Buckup ${ }^{2}$
}

\begin{abstract}
Biology and ecology of Aegla leptodactyla Buckup \& Rossi (Crustacea, Anomura, Aeglidae). The crustaceans of Aeglidae family occur in South America's freshwater environments, featuring as important links in the food chains. The present article has the intention to give an account of the results from investigations made from April/2000 to July/2001 on the biological and ecological features of Aegla leptodactyla Buckup \& Rossi, 1977, an endemic species from the head waters of the Rio Pelotas Basin in Rio Grande do Sul State, Brazil. The sampling was performed at the Rio da Divisa, tributary of Rio Pelotas, municipal district of São José dos Ausentes, Rio Grande do Sul. The animals were collected with a hand net ( $p u c ̧ a ́)$ at four different sites of the river. High contents of dissolved oxygen was verified, with a medium value of $108 \%$ and a low conductivity (avarage of $13.7 \mathrm{mS} / \mathrm{cm}$ ). The water mean temperature was $16^{\circ} \mathrm{C}$ and the $\mathrm{pH}$ remained neutral, average of 7.5 . The velocity of the water current varied from 0.54 to $0.78 \mathrm{~m} / \mathrm{s}$. A total of 1,323 males and 1,112 females of $A$. leptodactyla was sampled. Ovigerous females were observed from April through September and the smallest egg bearing female measured $14.09 \mathrm{~mm}$ cephalothorax length. The recruitment took place in November and December. The sex-ratio of the population was 1.19 males for 1 female.
\end{abstract}

KEY WORDS. Aegla leptodactyla, habitat, reproduction, recruitment

Os crustáceos anomuros do gênero Aegla Leach, 1820, ocorrem embaixo de pedras, de folhas e outros detritos depositados no leito de arroios e rios de correnteza no Brasil, Uruguai, Argentina, Paraguai, Bolívia e Chile, desde a profundidade de $320 \mathrm{~m}$, em lagos chilenos, até cerca de $4.500 \mathrm{~m}$ de altitude no noroeste argentino (BOND-BUCKUP \& BUCKUP 1994). Destacam-se como elos importantes nas cadeias alimentares nos ambientes límnicos pois são predadores de larvas de simulídeos hematófagos (MAGNI \& PY-DANIEL 1989) e constituem importante fonte alimentar para aves, rãs, jacarés e peixes (ARENAS 1974). A distribuição das espécies da família Aeglidae está restrita às regiões subtropical e temperada da América do Sul, sendo o limite norte de ocorrência o Município de Franca, no Estado de São Paulo, Brasil, e ao sul, a Ilha de Madre de Diós, Província de Ultima Esperanza, Chile (BOND-BUCKUP \& BUCKUP 1994).

Um dos primeiros trabalhos que trataram da biologia e ecologia de Aegla foi realizado no Chile, por MoucheT (1932), com Aegla laevis (Latreille, 1818). Outros trabalhos que relatam o habitat e o período reprodutivo de espécies de Aegla são de

1) Contribuição número 383 do Departamento de Zoologia, Instituto de Biociências, Universidade Federal do Rio Grande do Sul.

2) Programa de Pós-Graduação em Biologia Animal, Departamento de Zoologia, Instituto de Biociências, Universidade Federal do Rio Grande do Sul. Avenida Bento Gonçalves 9500, prédio 43435, 91501-970 Porto Alegre, Rio Grande do Sul, Brasil. 
BAHAMONDE \& LÓPEZ (1961) com Aegla laevis laevis (Latreille, 1818), de LÓPEZ (1965) com Aegla odebrechtii paulensis Schmitt, 1942, de RodRIGUES \& HEBLING (1978) com Aegla perobae Hebling \& Rodrigues, 1977, de BUENO \& BOND-BUCKUP (2000) com Aegla platensis Schmitt, 1942 e de SWIECH-AYOUB \& MASUNARI (2001a,b) com Aegla castro Schmitt, 1942. JARA (1977), ao descrever uma nova espécie chilena, $A$. rostrata, cita aspectos da ecologia e história natural da espécie.

Estudos sobre a biologia de espécies de Aegla no extremo Sul do Brasil limitam-se a Aegla platensis, por BUENO et al. (2000) e BUENO \& BOND-BUCKUP (2000), uma espécie que ocorre em uma região de baixa altitude onde as temperaturas são mais elevadas e extremos térmicos mais moderados. A presente pesquisa teve por objetivo conhecer o período reprodutivo, a fecundidade, o ingresso de juvenis na população, a razão sexual e as características do ambiente fluvial ocupado por Aegla leptodactyla, uma espécie que ocorre em uma região de maior altitude, cerca de 1.200 m (Município de São José dos Ausentes, Rio Grande do Sul). Partiu-se da hipótese de que nesta região A. leptodactyla está sujeita a temperaturas mais baixas da água durante o inverno, o que poderia determinar a existência de períodos de tempo mais circunscritos de postura e consequentemente, de recrutamento.

\section{MATERIAL E MÉTODOS}

As amostragens foram realizadas mensalmente, no período de abril de 2000

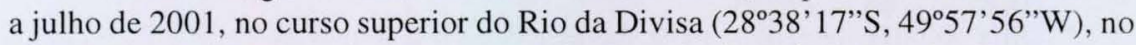
Município de São José dos Ausentes, Rio Grande do Sul. O Rio da Divisa é um afluente da margem esquerda do Rio Silveira, formador do Rio Pelotas e estende-se por uma área marginada pelos campos de cima da serra, com escassa vegetação marginal.

Levando-se em conta que o curso d'água apresenta variações na composição da flora aquática séssil, tipo de substrato e velocidade do curso d'água, optou-se por escolher quatro pontos de amostragem com base na constituição ecologicamente diferenciada do ambiente aquático. Para a captura dos animais foi utilizado um puçá de malha $3 \mathrm{~mm}$. Os exemplares capturados foram identificados taxonomicamente, e ainda, por sexo, através da observação, nas fêmeas, de presença de pleópodos no abdome e poro genital na coxa do terceiro par de pereiópodos. As fêmeas ovígeras tiveram registrada a medida de comprimento do cefalotórax, desde a margem interna da órbita até o bordo posterior da carapaça. Feitas as observações, os animais foram devolvidos ao mesmo local de origem.

Para verificar a existência de diferenças significativas entre o número de machos e de fêmeas, por mês e em todo conjunto de amostras, foi aplicado o teste do $X^{2}$. Registrou-se a presença de fêmeas ovígeras no período amostral e estimou-se a fecundidade pela contagem dos ovos em 14 fêmeas das amostras de setembro/2000, abril, maio, junho e julho/2001. A relação entre o número de ovos e o comprimento do cefalotórax foi descrita utilizando-se o seguinte modelo: $\mathrm{N}^{\circ}=\mathrm{a}$. $\mathrm{C}^{\mathrm{b}}$, onde $\mathrm{N}^{\mathrm{o}}$ é o número de ovos, $\mathrm{C}$ é o comprimento do cefalotórax e a e b são os parâmetros da regressão curvilinear. 
Para a estimativa do tamanho em que ocorre a primeira postura nas fêmeas, considerou-se a menor fêmea ovígera capturada. VAZzOLER (1981) propõe que o comprimento médio da primeira maturação gonodal seja o período em que $50 \%$ das fêmeas encontram-se maduras. Neste estudo não foi possível utilizar este método pois em nenhum mês de amostragem obteve-se 50\% de fêmeas ovígeras.

Os valores dos parâmetros físicos e químicos do ambiente em estudo como, $\mathrm{pH}$, temperatura da água, oxigênio dissolvido e condutividade, foram registrados em cada amostragem. Para tal foram utilizados um medidor portátil de $\mathrm{pH}$ (ColeParmer), um termo-oxímetro portátil (OXI 330/set-WTW) e um termo-salinômetro-condutivímetro (Yellow Springs Instruments). A velocidade da correnteza foi medida pelo método proposto por GALLAGHER \& STEVENSON (1999).

Para a análise química da água foram coletadas amostras nos meses de novembro/2000, abril/2001 e julho/2001 que foram encaminhadas ao Laboratório de Análises da Faculdade de Agronomia da Universidade Federal do Rio Grande do Sul. Também foram coletados espécies da flora aquática presente na área de estudo, encaminhadas ao Departamento de Botânica da Univeersidade Federal do Rio Grande do Sul e identificadas pelo Prof. Dr. Bruno Edgar Irgang.

\section{RESULTADOS E DISCUSSÃO}

Os exemplares de Aegla leptodactyla foram amostrados em uma área rasa do Rio da Divisa onde o leito fluvial tem a largura aproximada de 40 metros, junto à ponte da rodovia que liga Silveira à Capão Alto passando pela Barragem dos Touros. A profundidade no local situa-se entre 30 e $60 \mathrm{~cm}$, destacando-se, no fundo do rio, trechos com grande quantidade de seixos, de dimensões variadas e outros, com lajeados. Apenas em áreas de remanso ou de pouca correnteza pode-se encontrar areia, lodo argiloso e alguma matéria orgânica.

$\mathrm{Na}$ área de amostragem a velocidade da correnteza variou de $0,54 \mathrm{~m} / \mathrm{s}$ a $0,78 \mathrm{~m} / \mathrm{s}$ e observou-se a formação de corredeiras e pequenas quedas d'água ao longo do rio, o que contribui para os altos índices de oxigênio dissolvido registrados, atingindo um valor médio de $108 \%$ (Tab. I). A escassez de vegetação marginal ao longo do rio, não permite um aporte de matéria orgânica significante ao corpo d'água, sendo que, dessa forma, a condutividade elétrica é baixa (média de 13,7 $\mu \mathrm{S} / \mathrm{cm}$ ). Estas condições fazem com que o curso superior do rio possa ser considerado um ecossistema oligotrófico e característico da região do ritral, segundo a classificação de ILLIES (1961 apud SCHÄEFER 1985).

Durante o período de amostragem, a temperatura média da água foi de $16^{\circ} \mathrm{C}$, sendo a mínima $5,4^{\circ} \mathrm{C}$ registrada em junho/2001 e a máxima $24^{\circ} \mathrm{C}$ registrada em dezembro/2000 (Tab. I). Outras regiões onde foram estudadas espécies de Aegla, observou-se temperaturas médias semelhantes, porém as temperaturas mínimas foram superiores às encontradas no presente estudo. No Rio Maipo, Chile, segundo BAHAMONDE \& LÓPEZ (1961) a temperatura variou de 12,5 a $25^{\circ} \mathrm{C}$. Na Gruta da Peroba, no Estado de São Paulo, segundo RodRIGUES \& Hebling (1978) mediramse extremos de 11 e $22^{\circ} \mathrm{C}$. No Arroio do Mineiro, na bacia do Rio Gravataí, em Taquara, Rio Grande do Sul, segundo BUENO et al. (2000) a temperatura mínima 
foi de $13^{\circ} \mathrm{C}$ e a máxima de $22^{\circ} \mathrm{C}$. E na localidade denominada "Buraco do Padre", na Bacia do Rio Tibagi, Ponta Grossa, Paraná, a temperatura variou entre 15,8 e $22,3^{\circ} \mathrm{C}$ (SWIECH-AYOUB \& MASUNARI 2001a).

Tabela I. Valores de temperatura, $\mathrm{pH}$, oxigênio dissolvido e condutividade registrados de abril/2000 a julho/2001 no Rio da Divisa, São José dos Ausentes, Rio Grande do Sul.

\begin{tabular}{ccccc}
\hline Data de amostragem & Temperatura d'água $\left({ }^{\circ} \mathrm{C}\right)$ & $\mathrm{pH}$ & Oxigênio dissolvido $(\%)$ Condutividade $(\mathrm{mS} / \mathrm{CM})$ \\
\hline $07 / 04 / 2000$ & 18,0 & - & - & 20,0 \\
$03 / 06 / 2000$ & 11,4 & 7,60 & 126,0 & 15,0 \\
$01 / 08 / 2000$ & - & - & - & - \\
$02 / 09 / 2000$ & 14,3 & 8,10 & 113,7 & 15,0 \\
$30 / 09 / 2000$ & 17,8 & 7,90 & - & 18,0 \\
$29 / 10 / 2000$ & 16,3 & 7,80 & 95,0 & - \\
$25 / 11 / 2000$ & 18,9 & 7,20 & 80,2 & 15,0 \\
$21 / 12 / 2000$ & 24,0 & 7,60 & 108,0 & 10,0 \\
$17 / 01 / 2001$ & 18,7 & 8,10 & - & 11,0 \\
$18 / 02 / 2001$ & 20,2 & 8,20 & 93,8 & 10,0 \\
$18 / 03 / 2001$ & 19,8 & 6,90 & 84,0 & 11,0 \\
$22 / 04 / 2001$ & 15,1 & 6,90 & 94,4 & 15,4 \\
$20 / 05 / 2001$ & 10,7 & - & 98,8 & 14,6 \\
$23 / 06 / 2001$ & 5,4 & - & 85,2 & 13,7 \\
$31 / 07 / 2001$ & 13,4 & - & 97,1 & \\
\hline Média & 16,0 & 7,52 & 108,1 & \\
\hline
\end{tabular}

(-) Parâmetro não registrado.

No Rio da Divisa o pH manteve-se neutro, com média de 7,52, valor semelhante ao que foi registrados nos cursos d'água estudados por BUENO et al. (2000) e SWIECH-AYOUB \& MASUNARI (2001a). Os demais autores nada informaram sobre o $\mathrm{pH}$ dos ambientes estudados. Nos meses de maio/2000 e julho/2000 não foram realizadas amostragens devido a fatores ambientais, o que foi compensado por duas amostragens realizadas em setembro/2000.

$\mathrm{Na}$ análise química da água, os resultados foram comparados com os valores máximos permissíveis nas características organolépticas e químicas da água potável da Portaria n ${ }^{\circ}$ 36/GM, 1990 do Ministério de Estado da Saúde. O cobre (mg/L), zinco $(\mathrm{mg} / \mathrm{L})$, Manganês $(\mathrm{mg} / \mathrm{L})$, sulfato $(\mathrm{mg} / \mathrm{L})$ e dureza $(\mathrm{mg} \mathrm{CaCo} / \mathrm{L})$ ficaram dentro dos valores permissíveis, o que demonstra uma boa qualidade de água sem indicações de presença de efluentes de origem antrópica. Apenas o ferro $(\mathrm{mg} / \mathrm{L})$ ultrapassou os limites da normalidade na amostra de novembro/00 e abril/01 (Tab. II). Os elementos acima arrolados não apresentaram variações nas três amostragens realizadas, com exceção do ferro, que variou de $0,19 \mathrm{mg} / \mathrm{L}$ em julho/01 a $0,72 \mathrm{mg} / \mathrm{L} \mathrm{em}$ abril $/ 01$. Os valores do nitrogênio, fosfato $\left(\mathrm{P} / \mathrm{PO}^{-3} 4\right)$ potássio, cálcio, magnésio, sódio, boro e nitrogênio vinculado $\left(\mathrm{N}_{-} \mathrm{NH}_{4}{ }^{+}\right.$e N-NO$\left.{ }_{3}^{-}+\mathrm{N}^{-} \mathrm{NO}_{2}{ }^{-}\right)$encontram-se na tabela II.

Aegla leptodactyla foi registrada somente para a região nordeste do Estado do Rio Grande do Sul, onde vive em simpatria com Aegla camargoi Buckup \& Rossi, 1977 (BUCKUP \& Rossi 1977). No trecho amostrado do Rio da Divisa, os exemplares de A. leptodactyla foram encontrados debaixo de pedras e entre a vegetação juntamente $\operatorname{com} A$. camargoi, porém a última ocorre em número muito reduzido. 
Tabela II. Análise química da água do Rio da Divisa, proveniente das amostragens de novembro/2000, abril e julho/2001.

\begin{tabular}{|c|c|c|c|}
\hline \multirow{2}{*}{ Determinações } & \multicolumn{3}{|c|}{ Data das amostragens } \\
\hline & $25 / 11 / 2000$ & $22 / 04 / 2001$ & $31 / 072001$ \\
\hline $\mathrm{pH}$ & 6,40 & 6,40 & 6,20 \\
\hline Condutividade elétrica $-\mu \mathrm{S} / \mathrm{cm}$ & 18,29 & 17,23 & 14,58 \\
\hline Nitrogênio $(T K N)-m g / L$ & 0,82 & $<0,10$ & $<0,10$ \\
\hline Fósforo total - mg/L & 0,02 & $<0,01$ & $<0,01$ \\
\hline Potássio total - mg/L & 1,10 & 0,79 & 0,90 \\
\hline Cálcio total - mg/L & 1,00 & 0,84 & 4,60 \\
\hline Magnésio total - mg/L & 0,38 & 0,24 & 0,17 \\
\hline Cobre total - mg/L & $<0,01$ & $<0,02$ & $<0,02$ \\
\hline Zinco total - mg/L & $<0,01$ & $<0,01$ & $<0,01$ \\
\hline Ferro total - mg/L & 0,38 & 0,72 & 0,19 \\
\hline Manganês total - mg/L & 0,01 & 0,02 & $<0,01$ \\
\hline Sódio total - mg/L & 2,00 & 1,10 & 1,40 \\
\hline Boro total - mg/L & 0,02 & $<0,01$ & 0,02 \\
\hline Sulfato $-\mathrm{mg} / \mathrm{L}$ & 0,10 & 2,60 & $<1,00$ \\
\hline Dureza total-mg СaCO3/L (calc.) & 4,10 & 3,10 & 12,00 \\
\hline $\mathrm{N}-\mathrm{NH}_{4}{ }^{+}-\mathrm{mg} / \mathrm{L}$ & $<0,10$ & $<0,10$ & $<0,02$ \\
\hline $\mathrm{N}-\mathrm{NO}_{3}{ }^{-}+\mathrm{N}-\mathrm{NO}_{2}{ }^{-}-\mathrm{mg} / \mathrm{L}$ & $<0,10$ & $<0,10$ & $<0,10$ \\
\hline
\end{tabular}

A heterogeneidade física ao longo do Rio da Divisa resulta na formação de ambientes diferenciados para a ocupação pelas espécies. A amostragem diferenciada nos quatro pontos do Rio estenderam-se de outubro de 2000 a julho de 2001, servindo de base para as observações sobre as vinculações ambientais da espécie aqui considerada. Durante os 10 meses de amostragem, pode-se constatar que $A$. leptodactyla predominou em três, dos quatro pontos da área de estudo, tendo sido capturado um total de 1.878 indivíduos que perfazem $81,6 \%$ do total amostrado, enquanto que de $A$. camargoi foram capturados apenas 423 indivíduos, constituindo $18,4 \%$ do total.

O ponto 1 tem como característica o leito constituído por grande quantidade de seixos maiores e menores, estando ausente qualquer tipo de vegetação aquática enraizada. Nesta área a frequiência relativa de $A$. leptodactyla, durante o período amostral, foi $64,4 \%$ e de $A$. camargoi $35,6 \%$, sendo que o número de fêmeas ovadas de ambas espécies foi expressivo com 14 indivíduos de $A$. leptodactyla 10 de $A$. camargoi.

No ponto 2 as águas são rasas, cerca de $30 \mathrm{~cm}$ de profundidade, mas com forte correnteza e o leito formado de lajes, onde encontram-se aderidas grandes quantidades de plantas aquáticas do gênero Podostemum sp., o que concorda com as observações de SCHÄFER (1985), que destaca a distribuição das espécies da família Podostemonaceae na região do ritral de rios tropicais e subtropicais, sendo uma vegetação aquática com adaptação especial para permanência em habitat com forte correnteza. Neste ambiente é encontrada a maior abundância da espécie em estudo e os indivíduos representaram $98,8 \%$ do total, porém nenhuma fêmea ovígera foi registrada nesta área. A frequiência relativa de $A$. camargoi foi inexpressiva $(1,2 \%)$. O grande número amostral deve-se, além da maior densidade da espécie, a um maior esforço de captura neste ambiente. Para exemplares de A. prado Scmitt, 
1942 (= A. lenitica Buckup \& Rossi, 1977) coletados no Banhado do Taim (Jongh 1983 dados não publicados) também foi constatada maior abundância de animais nas zonas que possuem concentração de macrófitas. Grande quantidade de juvenis foram capturados nesta área, o que pode ser explicado pelo ambiente favorável estabelecido pela presença da vegetação do gênero Podostemum onde, além da proteção contra a forte correnteza, os juvenis encontram grande quantidade de larvas de insetos que servem como alimento. Observações semelhantes foram feitas por BAHAMONDE \& LÓPEZ (1961) que constataram a presença de juvenis de A. laevis laevis sobre algas filamentosas (Vaucheria e Cladophora) e nos ramos de Elodea, Miriophyllum e Nasturtium. A preferência de juvenis por zonas de menor correnteza, como entre folhas submersas, troncos caídos, pedregulhos ou raízes de vegetais também foi constatada por LÓPEZ (1965), RODRIGUES \& HEBLING (1978), BUENO $\&$ BOND-BUCKUP (2000) e SWIECH-AYOUB \& MASUNARI (2001a).

O ponto 3 possui solo arenoso com poucos pedregulhos e com grande quantidade de Ciperaceas, compreendendo espécies como Scirpus californicus e Eleocharis sp. Por ser uma área de remanso e com presença de vegetação, torna-se um local de difícil coleta. Apesar do pequeno número amostral, nesta zona foram encontrados quatro fêmeas ovígeras e os maiores espécimens de A. leptodactyla, três machos na classe de comprimento $21 \mathrm{~mm}$ e um macho na classe $22 \mathrm{~mm}$. Neste ponto A. leptodactyla representou $77,9 \%$ e $A$. camargoi $22,1 \%$ da amostra.

O quarto ponto de coleta se caracteriza pela presença de sedimento orgânico e abundante diversidade de macrófitas aquáticas, entre elas representantes de Alismataceae (Echinodorus argentinensis), Cyperaceae (Scirpus submersus, S. californicus), Halorrhagaceae (Myriophyllum aquaticum), Isoetaceae (Isoetes sp.), Lamiaceae, Mayacaceae (Mayaca sp.), Onagraceae (Ludwigia sp.), Polygonaceae (Polygonum meissnerianum), Ranunnculaceae (Ranunculus sp.) e Scrophulariaceae (Bacopa monnieri e Micranthemum umbrosum). Encontra-se também, neste ambiente, algas rodifíceas do gênero Batrachospermum sp. (Batrachospermaceae), que estão aderidas ao substrato rochoso. Segundo ESTEVES (1998), as macrófitas aquáticas além de fundamentais na cadeia de herbivoria e detritivoria e da utilização de sua área para a desova e refúgio de diversos organismos, exercem grande influência sobre o metabolismo dos ecossistemas aquáticos continentais, pois, permitem a sedimentação de material alóctone e se constituem na principal comunidade produtora de matéria orgânica do ecossistema. Nesta área, a freqüência relativa de $A$. camargoi foi $60 \%$, sendo registradas oito fêmeas ovígeras, enquanto que, ao contrário dos outros três pontos, a frequiência de $A$. leptodactyla foi inferior, $40 \%$. A presença destas espécies em uma área com fundo lodoso e com acúmulo de sedimentos de natureza orgânica não condiz com as observações de BAHAMONDE \& LOPÉZ (1961) que não observaram a ocorrência e A. laevis laevis em fundos com grande sedimentação e com areia.

Pela análise das vinculações dos animais aos quatro ambientes identificados, observou-se, pelo maior numero de indivíduos encontrados, que tanto adultos como jovens de A. leptodactyla, tem preferência pelo ambiente do ponto 2 , ou seja, dominado pelas plantas aquáticas, predominando os representantes do gênero Podostemum sp. 
Durante as amostragens, foram capturadas apenas 24 fêmeas ovígeras de $A$. leptodactyla que representam apenas $2,16 \%$ do total de fêmeas capturadas. Este número relativamente baixo pode ser resultado de migração das fêmeas ovígeras para as margens do rio, onde se refugiam sob as pedras, como já foi relatado por BAHAMONDE \& LÓPEZ (1961), BURNS (1972) e SWIECH-AYOUB \& MASUNARI (2001b) ou em áreas com acúmulo de vegetação (LÓPEZ 1965, BUENO \& BONDBUCKUP 2000). Nestes lugares, a coleta dos animais torna-se muito difícil, devido à fraca correnteza e a pouca profundidade do rio.

Na figura 1 observa-se a ocorrência de fêmeas ovígeras de Aegla leptodactyla no período de abril/2000 a setembro/2000 e de abril/2001 a julho/2001. Embora em abril/2000 o número de fêmeas ovígeras não tenha sido expressivo, no mesmo mês do ano seguinte ocorre a maior freqüência absoluta destas. A estação do aparecimento de fêmeas ovígeras na população muitas vezes é abordada como o período reprodutivo da espécie, mas as fases do ciclo reprodutivo envolvem, como já mencionado por SASTRY (1983), além da postura dos ovos, transformações internas anteriores, como o desenvolvimento ovariano e a vitelogênese.

O período registrado com a presença de fêmeas ovígeras em A. leptodactyla, assim como da maioria das espécies estudadas, abrange cerca de seis meses e coincide com os meses mais frios, ou seja, desde o final do outono até o início da primavera. Em A. laevis laevis, BAHAMONDE \& LÓPEZ (1961) registraram o período de presença de fêmeas ovígeras de março a outubro. Aegla odebrechtii paulensis e Aegla castro têm o período compreendido entre maio/junho e outubro (LÓPEZ 1965; SWIECH-A YOUB \& MASUNARI 2001b). JARA (1977) observou a presença de fêmeas ovígeras de A. rostrata a partir de abril e RODRIGUES \& HEBLING (1978) registraram o período entre abril e outubro para A. perobae. Fêmeas ovígeras de A. prado foram registradas de maio a novembro e, no cultivo experimental, apesar da desova iniciar no mesmo mês, o término se dá em janeiro (Jongh, 1983 dados não publicados). O período de desova de espécies cavernícolas de Aegla do Vale do Alto do Ribeira foi entre maio e outubro (Moracchioli, 1994 dados não publicados). Diferentemente das demais espécies, fêmeas ovígeras de A. platensis foram encontradas durante quase todo o ano, embora apresentem um pico de frequiência em julho (BUENO \& BOND-BUCKUP 2000).

Com base nestas informações pode-se notar que a reprodução da maioria das espécies de Aegla estudadas segue, de uma maneira geral, o padrão descrito por RODRIGUES \& HEBLING (1978), onde a postura dos ovos ocorre no outono, a incubação no inverno e a eclosão na primavera. Contudo, apesar de se observar uma correlação entre o período reprodutivo e a temperatura, não é este o único mecanismo indutor da reprodução, sendo que outros fatores ambientais, tais como, fotoperíodo e disponibilidade de alimento também são determinantes no ciclo (SASTRY 1983).

$\mathrm{O}$ ingresso dos juvenis na amostra em estudo foi registrado apenas em novembro e dezembro, período semelhante ao registrado para Aegla perobae na Gruta da Peroba, na Serra de São Pedro, no Estado de São Paulo, onde os juvenis surgem em outubro e novembro (RODRIGUES \& HEBLING 1978). Em A. laevis laevis e A. odebrechtii paulensis o surgimento dos juvenis ocorreu em setembro e outubro (BAHAMONDE \& LÓPEZ 1961; LÓPEZ 1965). Juvenis de Aegla castro são registrados 
para todo o período amostral, com o pico de recrutamento em abril (SWIECH-AYOUB \& MASUNARI 2001b). Já BUENO \& BOND-BUCKUP (2000), apesar de terem visto fêmeas ovígeras de A. platensis ao longo de quase todo o ano, registraram o aparecimento de juvenis apenas nas amostragens de agosto e outubro.

Nas fêmeas ovígeras de A. leptodactyla capturadas nos meses de julho, agosto e setembro foi possível observar a presença de olhos nos embriões, o que indica que os mesmos já haviam percorrido parte importante da embriogênese. Assim, as fêmeas ovígeras observadas em abril poderiam ter vindo a eclodir seus juvenis em outubro, isto se aceitarmos a hipótese de BAHAMONDE \& LÓPEZ (1961) sobre um período de incubação de cinco meses, tal como teria ocorrido em A. laevis laevis. Mais recentemente, SWIECH-AYOUB \& MASUNARI (2001b), tendo examinado Aegla castro, emitem hipóteses que vão na mesma direção, ou seja, de que esta espécie apresentaria um tempo de incubação que duraria cinco a seis meses. RODRIGUES \& HEBLING (1978) relatam em A. perobae, espécie com o ciclo reprodutivo muito semelhante ao da espécie aqui estudada, que os juvenis eclodem no início de outubro mas, após a eclosão, estes permanecem sob o abdome da fêmea durante 8 a 12 dias. Não se pode rejeitar a hipótese de que fenômeno idêntico possa ocorrer em A. leptodactyla, embora não se tenha encontrado juvenis aderidos ao abdome das fêmeas durante as amostragens.

O tamanho médio das fêmeas ovígeras de A. leptodactyla foi $16,98 \mathrm{~mm}$ de comprimento de cefalotórax, sendo que a maior frequêencia absoluta foi registrada no intervalo de classe de 18-19 mm de comprimento de cefalotórax (Fig. 2). O tamanho em que ocorre a primeira postura foi estimado pelo tamanho da menor fêmea ovígera capturada, ou seja $14,09 \mathrm{~mm}$, medida atingida com aproximadamente 250 dias de vida. Este tamanho, porém, está provavelmente superestimado, visto que, além do pequeno número amostral, em outras espécies estudadas foram registrados tamanhos inferiores. Em A. laevis laevis fêmeas ovígeras foram registradas a partir de $12,5 \mathrm{~mm}$ de comprimento de carapaça, em A. paulensis a partir de $11,5 \mathrm{~mm}$, em A. platensis $9,87 \mathrm{~mm}$ e em A. castro $12,3 \mathrm{~mm}$ (BAHAMONDE \& LÓPEZ 1961; LÓPEZ 1965; BUENO \& BOND-BUCKUP 2000; SWIECH-AYOUB \& MASUNARI 2001b). Nos exemplares de A. camargoi capturados juntamente com A. leptodactyla foi registrado o menor tamanho de fêmea ovígera, com $8,31 \mathrm{~mm}$ de comprimento de cefalotórax. BUENO \& BOND-BUCKUP (2000) verificaram, pela maior frequiência de fêmeas ovígeras, que $A$. platensis atinge a maturidade sexual, entre o $378^{\circ}$ e $467^{\circ}$ dia de vida, com tamanho de cefalotórax entre 14,40 e 15,60 mm de comprimento.

Pela análise do menor e maior tamanho de comprimento cefalotorácico das fêmeas ovígeras capturadas, $14,09 \mathrm{~mm}$ e $19,53 \mathrm{~mm}$, respectivamente, pode-se verificar a presença de dois grupos etários sexualmente ativos, à semelhança do observado por BAHAMONDE \& LÓPEZ (1961), BUENO \& BOND-BUCKUP (2000) e SWIECH-AYOUB \& MASUNARI (2001b).

A comparação dos dados de comprimento de cefalotórax de fêmeas ovígeras obtidos na presente investigação com os resultados apresentados por BAHAMONDE \& LÓPEZ (1961), LÓPEZ (1965), RODRIGUES \& HEBLING (1978) e SWIECH-AYOUB \& MASUNARI (2001a,b) fica prejudicada pela circunstância de estes terem sido obtidos com a inclusão do rostro. 

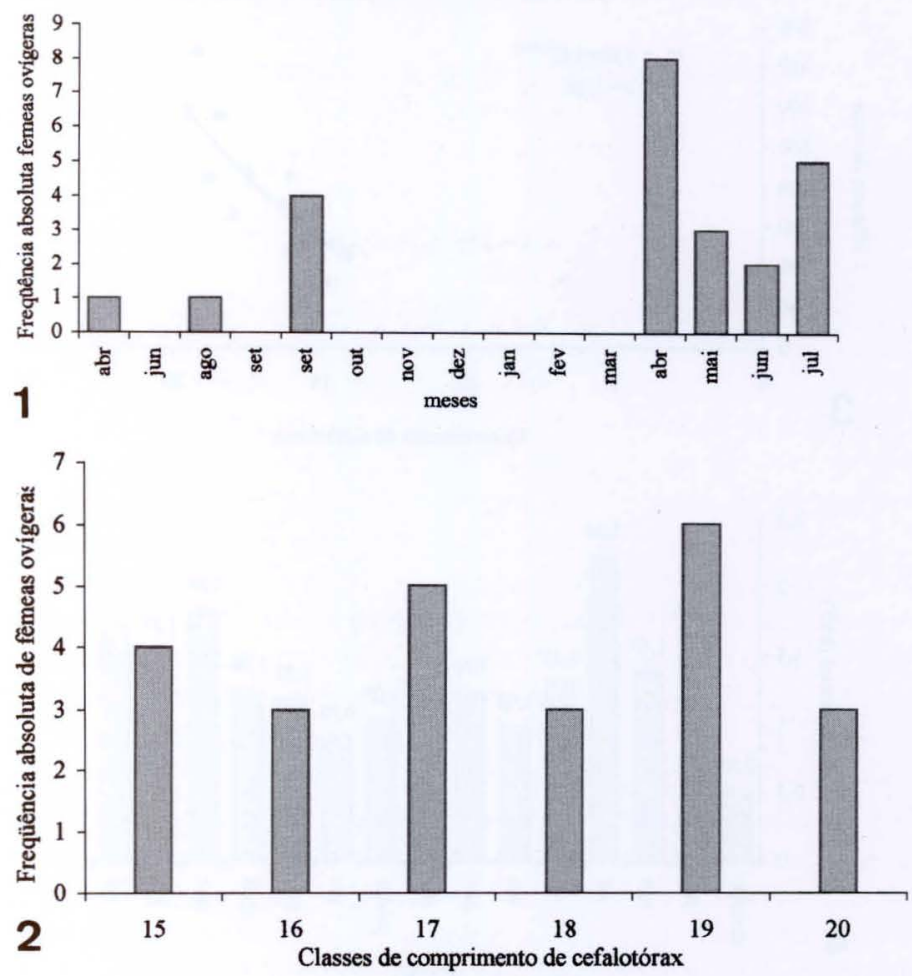

Figs 1-2. Freqüências absolutas de fêmeas ovigeras de Aegla leptodactyla amostrados de abril/2000 a julho/2001, no Riio da Divisa, São José dos Ausentes, Rio Grande do Sul: (1) por mês de amostragem; (2) por intervalo de classes de comprimento do cefalotórax $(\mathrm{mm})(15$ : 14,0-'15,0; 16: 15,0-'16,0; 17: 16,0-'17,0; 18: 17,0-'18,0; 19: 18,0-'19,0; 20: 19,0-'20,0).

Para a estimativa da fecundidade foram analisadas as massas de ovos de 14 fêmeas. A relação fecundidade/comprimento do cefalotórax para um total de 14 fêmeas segue um modelo curvilinear e corresponde a equação: $\mathrm{No}=0,0495 . \mathrm{C}^{2,924}$ (Fig. 3). Para A. leptodactyla foi utilizado o modelo de equação exponencial por ter apresentado um coeficiente de determinação maior $(r=0,86)$. Diferentemente do encontrado no presente trabalho, LópEZ (1965) verifica a existência de regressão linear do número de ovos para o comprimento de fêmeas de A. odebrechtti paulensis, como também foi constatado para A. lenitica (Jongh, 1983 dados não publicados). Modelos lineares em estudos de fecundidade também foram encontrados para camarões do gênero Macrobrachium Bate, 1868, como verificado por BOND \& BuCKUP (1982), VALENTI et al. (1989) e SOUZA \& FONTOURA (1995). Já RoDRIGUES \& HEBLING (1978) não constataram a existência de correlação significativa entre o tamanho do corpo e o número de ovos em $A$. perobae.

O número médio de ovos em fêmeas de $A$. leptodactyla foi 202,2, com variação de 115 ovos em uma fêmea de $14,09 \mathrm{~mm}$ de comprimento de cefalotórax a 368 ovos em uma fêmea de $19,18 \mathrm{~mm}$ de comprimento. A fecundidade de $A$. 

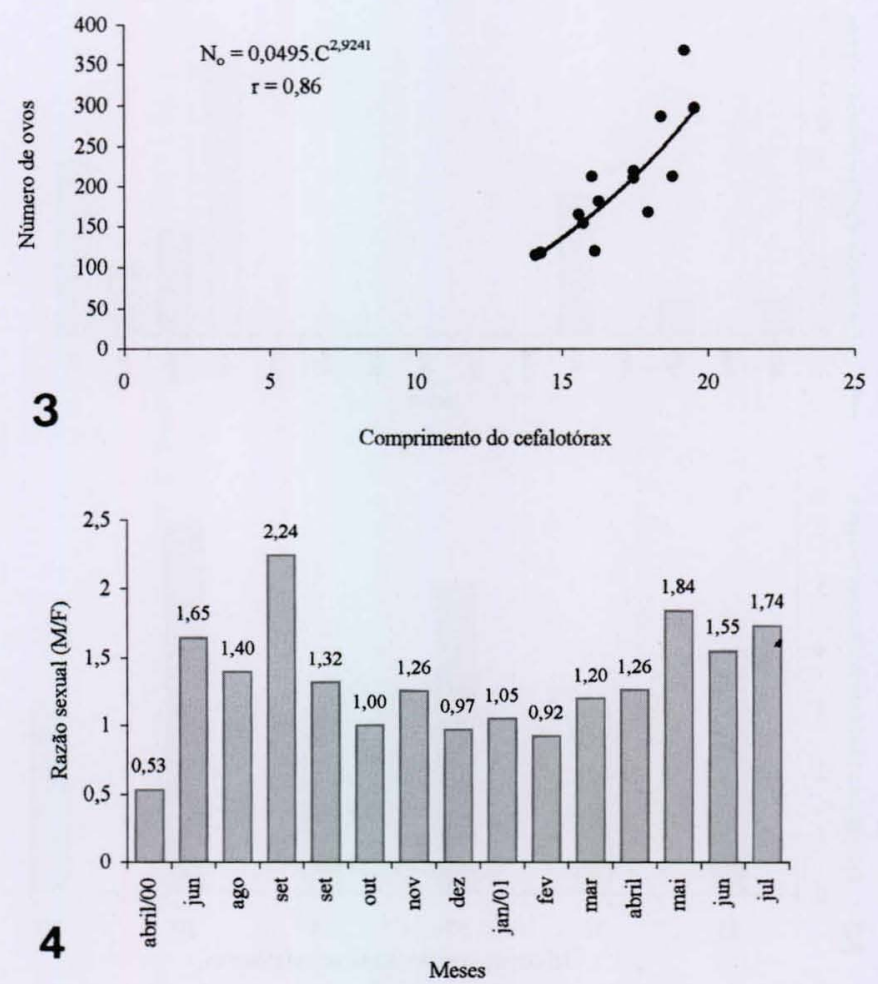

Figs 3-4. Aegla leptodactyla amostrada no Rio da Divisa, São José dos Ausentes, Rio Grande do Sul: (3) relação entre o número de ovos e o comprimento do cefalotórax de fêmeas ovigeras amostradas em agosto/2000, setembro/2000, abril/2001, maio/2001, junho/2001 e julho/2001; (4) razão macho/fêmea, por mês de amostragem, de exemplares amostrados de abril/2000 a julho/2001.

leptodactyla está próxima à encontrada para Aegla laevis laevis onde foram registrados 120 e 400 ovos para fêmeas de $12,5 \mathrm{~mm}$ e $22,5 \mathrm{~mm}$ de comprimento, respectivamente (BAHAMONDE \& LÓPEZ 1961). Em Aegla odebrechtii paulensis a fecundidade foi inferior, sendo registradas fêmeas de $15 \mathrm{~mm}$ de comprimento com 64 ovos e $17 \mathrm{~mm}$ com 113 ovos (LÓPEZ 1965).

A razão de sexos anual de $A$. leptodactyla foi 1,19 machos para cada fêmea (Fig. 4). Pela análise do $X^{2}\left(X^{2}=18,28\right)$, verifica-se a predominância significativa (com nível de significância de $99 \%$ ) de machos ao longo do período amostral. $\mathrm{Na}$ razão de sexos mensal, verifica-se a predominância significativa de machos nas duas coletas realizadas em setembro/2000 $\left(X^{2}=13,78\right.$ e $\left.X^{2}=4,02\right)$, em maio/01 $\left(X^{2}=\right.$ $12,75)$,em junho/01 $\left(X^{2}=6,72\right)$ e em julho/01 $\left(X^{2}=11,30\right)$. O predomínio numérico de machos sobre fêmeas também foi constatado por LÓPEZ (1965) para A. paulensis e por RODRIGUES \& HEBLING (1978) para A. perobae que encontraram uma razão de 5:1 entre setembro e novembro. Segundo BAHAMONDE \& LÓPEZ (1961), VAZZOLER (1981), SWIECH-AYOUB \& MASUNARI (2001b), a mortalidade ou o com- 
portamento diferencial são alguns fatores que podem atuar de modo diferenciado sobre machos e fêmeas, determinando o predomínio de um dos sexos durante uma fase do ciclo de vida.

BUENO \& BOND-BUCKUP (2000), que examinaram A.platensis e SWIECHAYOUB \& MASUNARI (2001b) que estudaram A. castro, não constataram diferenças significativas na proporção de sexos ao longo do período amostral, embora tenham encontrado um maior número de machos nas amostras. BAHAMONDE \& LÓPEZ (1961) encontraram uma razão média de 1:1 em Aegla laevis laevis, mas observaram que esta situação varia muito durante o ano.

Nas investigações que conduziram aos resultados aqui relatados partiu-se da hipótese de que na região de São José dos Ausentes A. leptodactyla estaria sujeita a temperaturas mais baixas da água durante o inverno, o que poderia determinar a existência de períodos de tempo mais circunscritos de postura e consequentemente, de recrutamento. A suposição mostrou-se procedente quando a biologia de $A$. leptodactyla é comparada com aquela de A. platensis, que ocorre em regiões de menor altitude e com temperaturas mais quentes.

\section{REFERÊNCIAS BIBLIOGRÁFICAS}

ARENAS, R.L. 1974. La cordillera de la costa como refugio de la fauna dulcícola preglacial. Arch. Biol.

Med. Exp., Chile, 10: 1-40.

Bahamonde, N. \& M.T. López. 1961. Estudios biológicos en la populación de Aegla laevis laevis

(Latreille) de el Monte (Crustacea, Decapoda, Anomura). Inv. Zool. Chil. 7: 19-58.

Bond, G. \& L. BUCKup. 1982. O ciclo reprodutor de Macrobrachium borelli (Nobili, 1896) e Macrobrachium potiuna (Müller, 1880) (Crustacea, Decapoda, Palaemonidae) e suas relações com a temperatura. Rev. Brasil. Biol., Rio de Janeiro, 42 (3): 473-483.

Bond-Buckup, G. \& L. Buckup. 1994. A família Aeglidae (Crustacea, Decapoda, Anomura). Arch. Zool., São Paulo, 2 (4): 159-346.

Buckup, L. \& A. Rossi. 1977. O gênero Aegla no Brasil (Crustacea, Decapoda, Anomura, Aeglidae).

Rev. Brasil. Biol., Rio de Janeiro, 37 (4): 879-892.

Bueno, A.A.P. \& G. Bond-Buckup. 2000. Dinâmica populacional de Aegla platensis Schmitt

(Crustacea, Decapoda, Aeglidae). Revta bras. Zool. 17 (1): 43-49.

Bueno, A.A.P.; G. Bond-Buckup \& L. Buckup. 2000. Crescimento de Aegla platensis Schmitt em ambiente natural (Crustacea, Decapoda, Aeglidae). Revta bras. Zool. 17 (1): 51-60.

BuRns, J.W. 1972. The distribution and life history of south american freshwater crabs (Aegla) and their role in trout streams and lakes. Trans. Amer. Fish. Soc., Bethesda, 101 (4): 595-607.

Esteves. F.A. 1998. Fundamentos de limnologia. Interciência, Rio de Janeiro, 602p.

Gallagher, A.S.P. \& N.J. Stevenson. 1999. Stream Flow. In: M.B. Bain \& N.J. Stevenson (Eds).

Common methods in aquatic habitat assessment. New York, American Fisheries Society, 216p.

JARA, C. 1977. Aegla rostrata n. sp., (Decapoda, Aeglidae), nuevo crustáceo dulceacuícola del Sur de

Chile. Stud Neotrop. Fauna Environ., Amsterdam, 12: 165-176.

LóPEZ, M.T. 1965. Estudios biologicos en Aegla odebrechtti paulensis, Schmitt (Crustacea, Decapoda, Anomura). Bol. Zool. Fac. Fil. Cien. Letras, São Paulo, 25: 301-314.

MaGnI, S.T. \& V. PY-DANIEL. 1989. Aegla platensis Schmitt, 1942 (Decapoda, Anomura) um predador de imaturos de Simulidae (Diptera, Culicomorpha). Rev. Saúde Púb., São Paulo, 23 (3): 258-259.

Mouchet, S. 1932. Notes sur la biologie du galathéide Aegla laevis (Latr.). Bull. Soc. Zool. Fr., Paris, 57 (59): $316-340$.

Rodrigues, W. \& N.J. Hebling. 1978. Estudos biológicos em Aegla perobae Hebling \& Rodrigues, 1977 (Decapoda, Anomura). Rev. Brasil. Biol., Rio de Janeiro, 38 (2): 383-390.

SASTRY, A.N. 1983. Ecological aspects of reproduction, p. 179-255. In: D.E. BLISS (Ed.). The Biology 
of Crustacea: Environmental Adaptation. New York, Academic Press, Vol. 8, 383p.

SCHÄFER, A. 1985. Fundamentos de ecologia e biogeografia das águas continentais. Porto Alegre, Ed. UFRGS, 532p.

SouzA, G.D. \& N.F. FontouRA. 1995. Crescimento de Macrobrachium potiuna no Arroio Sapucaia, município de Gravataí, Rio Grande do Sul (Crustacea, Decapoda, Palaemonidae). Rev. Brasil. Biol., Rio de Janeiro, 55: 51-63.

Swiech-Ayoub, B.P. \& S. Masunari. 2001a. Flutuações temporal e espacial de abundância e composição de tamanho de Aegla castro Schmitt (Crustacea, Anomura, Aeglidae) no Buraco do Padre, Ponta Grossa, Paraná, Brasil. Revta bras. Zool. 18 (3): 1003-1017.

Swiech-Ayoub, B.P. \& S. MASUnARI. 2001b. Biologia reprodutiva de Aegla castro Schmitt (Crustacea, Anomura, Aeglidae) no Buraco do Padre, Ponta Grossa, Paraná, Brasil. Revta bras. Zool. 18 (3): 1019-1030.

VALENTI, W.C.; J.T.C. MELLO \& V.L. LOBÃo. 1989. Fecundidade em Macrobrachium acanthurus (Wiegmann, 1836) do Rio Ribeira de Iguape (Crustacea, Decapoda, Palaemonidae). Revta bras. Zool. 6 (1): 9-15.

VAZZOLER, A.E.A.M. 1981. Manual de métodos para estudos biológicos de populações de peixes: reprodução e crescimento. Brasília, CNPq, Programa Nacional de Zoologia, 108p.

Recebido em 08.IV.2002; aceito em 03.X.2002. 